\title{
Severe Myocardial Infarction Caused by Excessive Cannabis Consumption
}

Ramia Bougrine $^{1}$, Mohamed Boutaybi ${ }^{1}$, Soumia Boulouiz ${ }^{1}$, Noha Elouafi ${ }^{1}$, Zakaria Bazid ${ }^{2}$

1. Cardiology, Mohammed I University/Mohammed VI University Hospital, Oujda, MAR 2. Cardiology, Mohammed I University/Mohammed VI University Hospital/Epidemiological Laboratory of Clinical Research and Public Health, Oujda, MAR

Corresponding author: Ramia Bougrine, bougrineramia1@gmail.com

\begin{abstract}
The cardiovascular effects of cannabis are not well known. Cannabis use has been shown to cause arrhythmia, including ventricular tachycardia, sudden death, and increase in the risk of myocardial infarction (MI). We report a 62-year-old woman with chronic cannabis abuse inducing MI complicated by cardiogenic shock, chronic dilated cardiomyopathy, and atrial fibrillation.
\end{abstract}

Categories: Cardiology, Emergency Medicine, Other

Keywords: cannabis use, inferior-posterior myocardial infarction, coronary artery disease, coronary artery vasospasm

\section{Introduction}

Cannabis is one of the most popular illicit drugs in the world. It is often consumed for its euphoric and hallucinogenic effects [1], which could be a significant contributing factor to a cardiovascular event. However, cannabis as a cardiovascular factor should not be overlooked. Even though the exact role of this drug in the pathogenesis of coronary heart disease remains poorly understood, the legalization of cannabis would be a good demographic/sociological issue to discuss, which could increase the cardiovascular events in our society.

We report a case of severe myocardial infarction (MI) in an elderly woman chronically addicted to cannabis.

\section{Case Presentation}

A 62-year-old woman with a history of tobacco abuse (30 pack-years) and chronic cannabis use, presented with severe retrosternal chest pain with peripheral vascular collapse (weak peripheral pulses, pale skin), sweating, and vomiting after $30 \mathrm{~min}$ of excessive cannabis consumption, i.e. more than 15 cigarettes.

Review began 03/14/2021 Review ended 03/30/2021 Published 04/23/2021

\section{○ Copyright 2021}

Bougrine et al. This is an open access article distributed under the terms of the Creative Commons Attribution License CC-BY 4.0., which permits unrestricted use, distribution, and reproduction in any medium, provided the original author and source are credited.
The physical examination found a pale, agitated patient, with a blood pressure limit of 100/60 mmHg; the cardiovascular examination was normal; electrocardiogram (ECG) revealed ST-segment elevation in inferior and basal leads (Figure 1). An echocardiogram was performed, revealing dilated cardiomyopathy with global hypokinesia, a severely reduced ejection fraction (EF) of $20 \%$, and associated right ventricular dysfunction (Figure 2). After a drop in blood pressure, the patient was started on inotropic agents (dobutamine 10 gamma $/ \mathrm{kg} / \mathrm{min}$ ). We noted the disappearance of chest pain and regression of ST-segment elevation after hemodynamic state stabilization (Figure 3). A coronary angiogram which was performed at hour eight of chest pain showed normal coronary arteries without stenosis (Figure 4). The ECG monitoring showed atrial fibrillation at $100 \mathrm{bpm}$. Laboratory measurements showed elevation of cardiac biomarkers troponin (41600 $\mathrm{ng} / \mathrm{mL}$, the upper limit of normal $<26 \mathrm{ng} / \mathrm{mL}$ ). 


\section{Cureus}

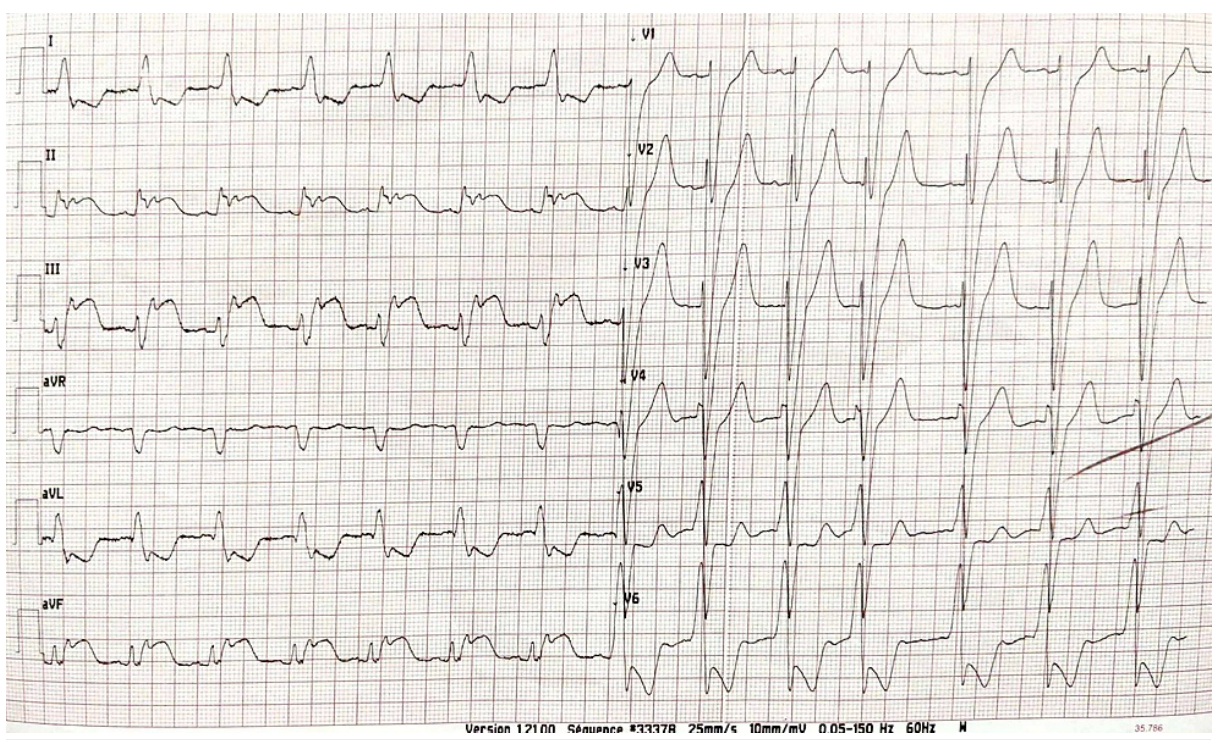

FIGURE 1: Electrocardiogram with ST-segment elevation in inferior leads.

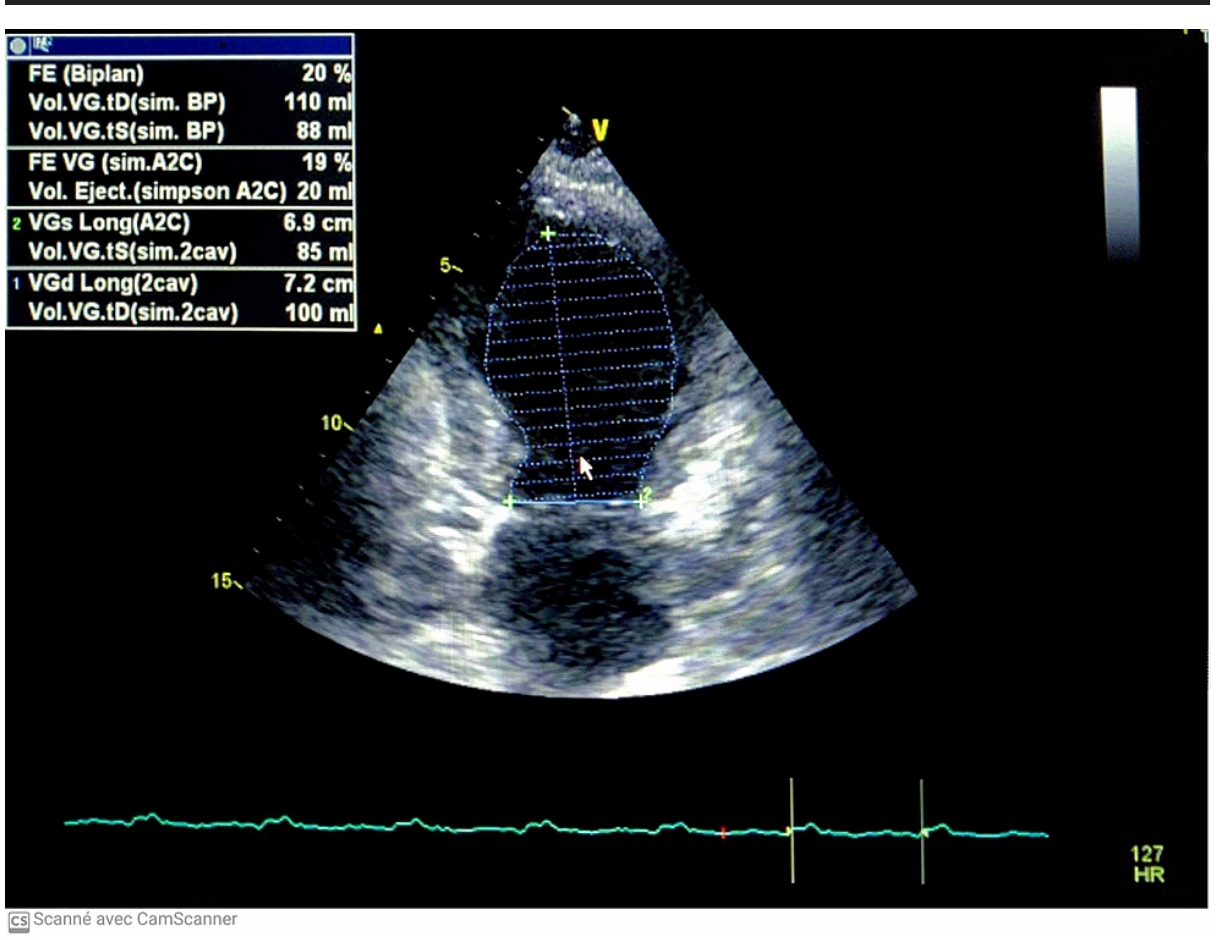

FIGURE 2: The echocardiography showed a dilated cardiomyopathy with severe EF $20 \%$.

$E F$, ejection fraction 


\section{Cureus}

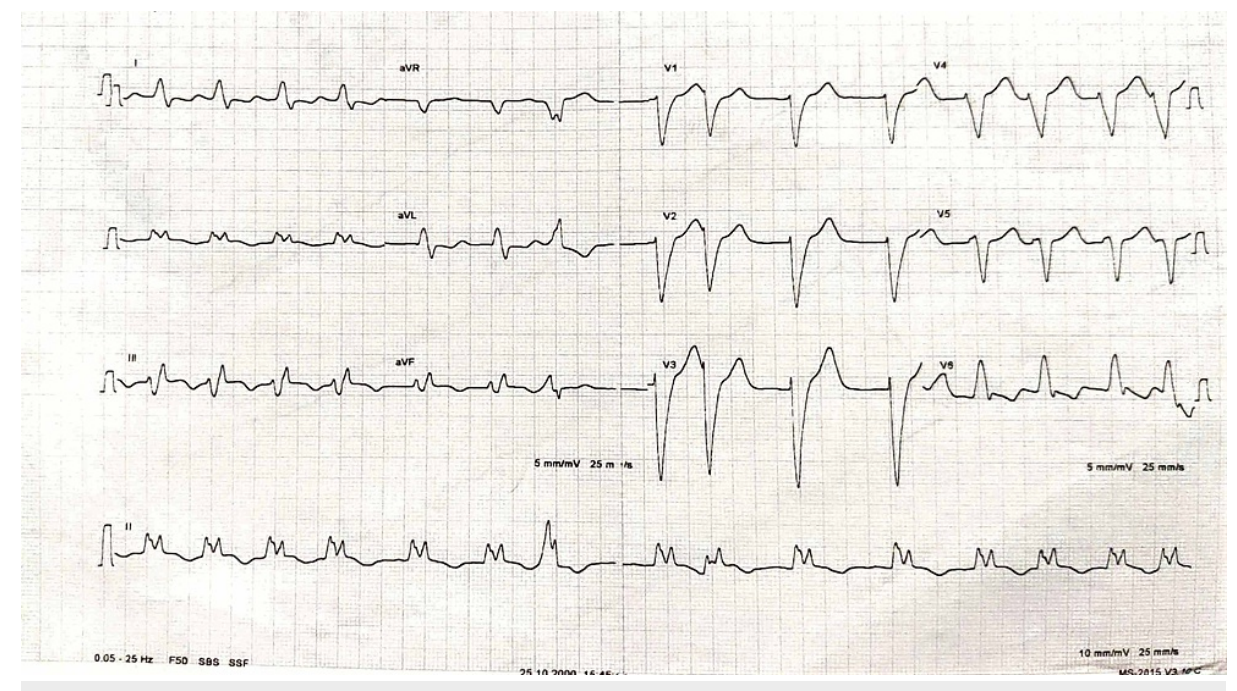

FIGURE 3: Regression of ST-segment elevation in inferior leads with atrial fibrillation.

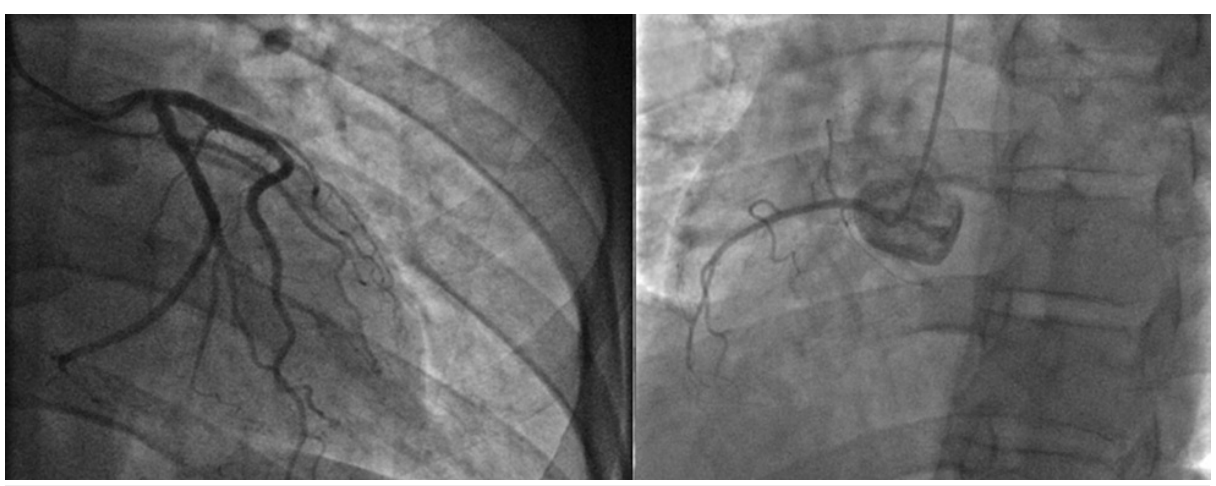

FIGURE 4: A coronary angiogram showed normal coronary arteries without stenosis (left dominance).

The patient was admitted to the ICU, and started on an IV vasodilator and inotrope agent. The hemodynamic status was stabilized after $48 \mathrm{~h}$, with the persistence of severe ventricular dysfunction and atrial fibrillation. The patient was discharged after a week with diltiazem, ACE inhibitor, diuretic; anticoagulation by rivaroxaban $20 \mathrm{mg}$ was initiated.

Clinical follow-up after three and six months later was favorable with nonrecuperation of a normal ventricular function.

\section{Discussion}

Cannabis is a common drug derived from the Cannabis sativa plant. Its physiological effects are mediated by the interaction of THC D9-tetrahydrocannabinol with the endocannabinoid system with at least two cannabinoid membrane receptors (CBR1 and CBR2). CBR1 is the most expressed in the central nervous system (brain, heart, blood, spleen, etc.), peripheral (artery, immune system), and autonomic nervous system, which acts by activation of the sympathetic nervous system, as well as by inhibition of the parasympathetic nervous system [2-3].

The relationship between cardiovascular events remains unknown. Regular cannabis consumption may increase the level of catecholamines, the level of carboxyhemoglobin, which limits the capacity of oxygen transport. A mismatch between increased oxygen demand and decreased myocardial oxygen supply can promote the onset of coronary syndrome, orthostatic hypotension, increased blood pressure, and cardiac workload [4]. Cannabis has also been described as having procoagulant effects since both receptors are expressed on the cells of the platelet membrane [5]; the other effect was tachyarrhythmia, supraventricular or ventricular can be explained by the high level of adrenaline following cannabis abuse [6]. Cannabinoids have also been shown to reduce myocardial contractility through effects mediated by CBR1 [7]. 
Myocardial infarction was also reported. Thrombus formation, coronary vasospasm, and coronary artery dissection are the three proposed mechanisms described in literature [8-9]. Casier et al. [3] reported that cannabis abuse was associated with severe coronary syndrome due to coronary spasm and MI with a total artery occlusion. Deharo et al. [10], Ghannem et al. [11], and Yurtdaş et al. [12] reported cases of excessive cannabis use induced MI after an exercise in healthy young men with a thrombotic occlusion. Finally it is still obscure, if cannabis contributes to coronary diseases in the same way as smoking [13], but these case studies indicate that cannabis can be a risk factor for MI in addicted persons.

In our case, the angiography revealed normal coronary arteries. The diagnosis of coronary vasospasm was accepted given the context and other cannabis complications. Also, due to the advanced age of our patient, it would be possible to have an associated atherosclerosis coronary lesion.

This case highlights the potential danger of cannabis especially in patients with chronic cannabis consumption [14].

The prevalence of coronary diseases caused by the consumption of cannabis may increase due to the legalization of this drug, which will increase potentially the incidence of MI in consumer patients [15].

\section{Conclusions}

This case highlights an unusual case in elderly women with excessive use of cannabis causing severe cardiovascular complications: MI with shock, arrhythmia, which should be systematically investigated in patients' consumers with a coronary syndrome, especially without a cardiovascular risk factor. Coronary vasospasm and intracoronary thrombus appear to be the two main mechanisms involved.

The treatment is essentially preventative and relies on stopping cannabis use, but with the legalization of cannabis consumption, we should be close to receiving more coronary syndrome and its complications.

\section{Additional Information \\ Disclosures}

Human subjects: Consent was obtained or waived by all participants in this study. Conflicts of interest: In compliance with the ICMJE uniform disclosure form, all authors declare the following: Payment/services info: All authors have declared that no financial support was received from any organization for the submitted work. Financial relationships: All authors have declared that they have no financial relationships at present or within the previous three years with any organizations that might have an interest in the submitted work. Other relationships: All authors have declared that there are no other relationships or activities that could appear to have influenced the submitted work.

\section{References}

1. Health Interview Survey Interactive Analysis. http://www.wiv-isp.be/epidemio/hisia.

2. Benowitz NL, Rosenberg J, Rogers W, Bachman J, Jones RT: Cardiovascular effects of intravenous delta-9tetrahydrocannabinol: autonomic nervous mechanisms. Clin Pharmacol Ther. 1979, 25:440-446. 10.1002/cpt1979254440

3. Casier I, Vanduynhoven $\mathrm{P}$, Haine $\mathrm{S}$, et al.: Is recent cannabis use associated with acute coronary syndromes? An illustrative case series. Acta Cardiol. 2014, 131-136.

4. Aryana A, Williams MA: Marijuana as a trigger of cardiovascular events: speculation or scientific certainty? Int J Cardiol. 2007, 118:141-14 4. 10.1016/j.ijcard.2006.08.001

5. Deusch E, Kress HG, Kraft B, Kozek-Langenecker SA: The procoagulatory effects of delta-9tetrahydrocannabinol in human platelets. Anesth Analg. 2004, 99:1127-1130. 10.1213/01.ANE.0000131505.03006.74

6. Singh A, Saluja S, Kumar A, Agrawal S, Thind M, Nanda S, Shirani J: Cardiovascular complications of marijuana and related substances: a review. Cardiol Ther. 2018, 7:45-59. 10.1007/s40119-017-0102-X

7. Bonz A, Laser M, Kullmer S, et al.: Cannabinoids acting on CB1 receptors decrease contractile performance. J Cardiovasc Pharmacol. 2003, 41:657-664.

8. Dandapantula HK, Spears JR, Chandu L, Katkuri H, Afonso L: Cigarette smoking and myocardial infarction in young men and women--"Let us not forget coronary vasospasm". Int J Cardiol. 2008, 127:402. 10.1016/j.ijcard.2007.05.002

9. Voigt P, Bach AG, Surov A: Coronary air embolism in a trauma patient. Clin Res Cardiol. 2017, 106:933-934. 10.1007/s00392-017-1134-X

10. Deharo P, Massoure PL, Fourcade L: Exercise-induced acute coronary syndrome in a 24-year-old man with massive cannabis consumption. Acta Cardiol. 2013, 68:425-428. 10.1080/AC.68.4.2988898

11. Ghannem M, Belhadj I, Tritar A, et al.: [Cannabis and acute coronary syndrome with ST segment elevation] . Ann Cardiol Angeiol (Paris). 2013, 62:424-428.

12. Yurtdaş M, Aydın MK: Acute myocardial infarction in a young man; fatal blow of the marijuana: a case report. Korean Circ J. 2012, 42:641-645.

13. Goyal H, Awad HH, Ghali JK: Role of cannabis in cardiovascular disorders . J Thoracic Dis. 2017, 9:2079-209.

14. Sharma N, Lee J, Aponte CS, et al.: Clinical characteristics and angiographic findings of acute myocardial infarction associated with marijuana use: consecutive case series. Scifed J Cardiol. 2017, 2:1000011. 


\section{Cureus}

15. Watson TM, Valleriani J, Hyshka E, Rueda S: Cannabis legalization in the provinces and territories: missing opportunities to effectively educate youth?. Can J Public Health. 2019, 110:472-475. 10.17269/s41997-01900209-0 